\title{
Aniridia-renal agenesis-psychomotor retardation syndrome
}

INSERM

\section{Source}

INSERM. (1999). Orphanet: an online rare disease and orphan drug data base. Aniridiarenal agenesis-psychomotor retardation syndrome. ORPHA:1064

Aniridia - renal agenesis - psychomotor retardation is an extremely rare syndrome reported in two siblings of non consanguineous parents that is characterized by the association of ocular abnormalities (partial aniridia, congenital glaucoma (see these terms), telecanthus) with frontal bossing, hypertelorism, unilateral renal agenesis (see this term) and mild psychomotor delay. There have been no further descriptions in the literature since 1974. 